\title{
A Detailed Analysis of Hispanic Learners' use of YouTube as a Tool to Reinforce the Learning Process in Higher Education
}

\author{
Mayken Espinoza, $\mathrm{MEF}^{1}{ }^{3}$, , Julio Barzola, Mg. ${ }^{1},{ }^{2}$, and Jorge Flores, $\mathrm{Mg} .^{4}$ \\ ${ }^{1}$ Escuela Superior Politécnica del Litoral, Ecuador, masespin@espol.edu.ec, jjbarzol@espol.edu.ec \\ ${ }^{2}$ Universidad de Guayaquil, Ecuador, julio.barzolam@ug.edu.ec \\ ${ }^{3}$ Lund University, Sweden, Mayken.Espinoza_Andaluz@energy.lth.se \\ ${ }^{4}$ Universidad Laica VICENTE ROCAFUERTE de Guayaquil, Ecuador, jfloresh@ulvr.edu.ec
}

\begin{abstract}
This paper gives a detailed information about how
the Hispanic learners take advantage of a group of videos on various topics of Physics. These topics are selected from the curriculum of a bachelor engineering education program (undergraduate studies) in a higher education institution (HEI). The videos are classified according to the topic involved, and the whole experiment is carried out during 2 years. The gap genre and demographic of Hispanic learners is addressed in the paper.

Keywords-Learning process, Youtube, Hispanic learners, higher education.
\end{abstract}

Digital Object Identifier (DOI):

http://dx.doi.org/10.18687/LACCEI2016.1.1.361

ISBN: 978-0-9822896-9-3

ISSN: 2414-6390

$14^{\text {th }}$ LACCEI International Multi-Conference for Engineering, Education, and Technology: "Engineering Innovations for Global Sustainability", 20-22 July 2016, San José, Costa Rica. 


\title{
A Detailed Analysis of Hispanic Learners' use of YouTube as a Tool to Reinforce the Learning Process in Higher Education
}

\author{
Mayken Espinoza, MEF ${ }^{1,3}$, Julio Barzola, Mg. ${ }^{1,2}$, and Jorge Flores, Mg. ${ }^{4}$ \\ ${ }^{1}$ Escuela Superior Politécnica del Litoral, Ecuador, masespin@espol.edu.ec, jjbarzol@espol.edu.ec \\ ${ }^{2}$ Universidad de Guayaquil, Ecuador, julio.barzolam@ug.edu.ec \\ ${ }^{3}$ Lund University, Sweden, Mayken.Espinoza_Andaluz@energy.lth.se \\ ${ }^{4}$ Universidad Laica VICENTE ROCAFUERTE de Guayaquil, Ecuador, jfloresh@ulvr.edu.ec
}

\begin{abstract}
This paper gives a detailed information about how the Hispanic learners take advantage of a group of videos on various topics of Physics. These topics are selected from the curriculum of a bachelor engineering education program (undergraduate studies) in a higher education institution (HEI). The videos are classified according to the topic involved, and the whole experiment is carried out during 2 years. The gap genre and demographic of Hispanic learners is addressed in the paper.

Keywords-Learning process, Youtube, Hispanic learners, higher education.
\end{abstract}

\section{INTRODUCTION}

Global internet usage, on an average, has been increasing during the last years around the world [1][2]. The presence of internet in diverse activities carried out for the human beings change their habits in different ways. Taking into account the manner in which the new generation of students acquires knowledge and their acquaintance with internet, it is not hard to say that the teaching-learning process for the future generations will coexist with tools based on internet.

There are different ways to introduce the internet tools in the educational process for different fields [3][4]. These ways can vary depending on the aims of the lectures or courses. These tools can be included in the educational process from a simple communication between the professor and students using the electronic mail, until a more complete and detailed platform with tutorial videos, forums, and evaluation systems for the assignments.

Currently, the tool included in the teaching-learning process plays an important role in the education systems at different levels, from the primary school to higher education. Some studies about the use of different internet tools in education have been carried out, for example, Wikipedia [5] or Web 2.0 [6]. One example of internet use on the teaching process is the massive open online course (MOOC); this modality has created a big impact on the society, and many Higher Education Institutions (HEIs) have taken part in it [7][8]. MOOCs allow the learners to acquire knowledge in the form of courses given by several universities around the world using different pedagogical practices [9]. In addition, a study comparing the online and face to face learning process has been carried out [10] showed that learning style and flexibility are important during the learning process.

Most of the MOOCs have a group of videos (10 - $40 \mathrm{~min}$ length) as means to give information to the learners. Based on the mentioned characteristic, the authors considered that one of the applicable ways to share the information with the students is video explanation, and therefore; a group of videos was developed. More details about the videos are given in the corresponding section.

For this work, a YouTube channel was created with the aim of sharing information about selected topics of Physics according to the curriculum of engineering programs of a South-American HEI. Although there are several YouTube channels with videos related to Physics, there is no independent research about the approach of this tool over the learners. What do the students think about the traditional lectures? Is the information the learners can find in an academic YouTube channel really helpful? What are the demographic characteristics of the Physics learners? Is there a significant genre difference of learners who are looking for Physics topics? These and other questions will be answered in this paper. The main objective of this study is to present the analytic results of the implemented experiment, and with the information presented in this paper, the readers can have a general insight of what a group of videos can achieve in different ways.

The rest of the paper is organized as follows: Section II explains the methodology applied in a general view. Section III refers to the characteristics of the videos: the selection of the topics, length of the videos and their topic classification. Section IV mainly focuses on the findings and discussions. Finally, the conclusions of the work are presented.

\section{METHODOLOGY}

Like most pedagogical researches, the aim of this work is to explain the different behaviors of the learners when they are exposed to a pedagogical tool. In this case, the pedagogical tool applied is a set of videos uploaded in a YouTube channel.

Digital Object Identifier (DOI): http://dx.doi.org/10.18687/LACCEI2016.1.1.361 ISBN: 978-0-9822896-9-3

ISSN: $2414-6390$

14 ${ }^{\text {th }}$ LACCEI International Multi-Conference for Engineering, Education, and Technology: "Engineering Innovations for Global Sustainability", 20-22 July 2016, San José, Costa Rica. 
More details about the topics and video characteristics are given in the next section.

The whole project was carried out in 24 months. The complete period is divided into four clearly defined subperiods or stages. Table I shows the monthly distribution of each sub-period. During each sub-period, different activities were performed.

TABLE I

MONTHLY DISTRIBUTION ALONG THE PROJECT
\begin{tabular}{|c|c|c|}
\hline Year & Period & No. of months \\
\hline 2014 & $1^{\text {st }}$ & 6 \\
& $2^{\text {nd }}$ & 6 \\
\hline 2015 & $3^{\text {rd }}$ & 9 \\
& $4^{\text {th }}$ & 3 \\
\hline \multicolumn{2}{|c|}{} & 24 \\
\hline
\end{tabular}

As mentioned, for each sub-period, different activities were performed such as: stage for recording and video publication, stage for answering questions from the learners and interactions, and finally the corresponding stage to collect the information and measure the approach of the experiment.

\begin{tabular}{c|c|c|c|c}
\hline \multirow{2}{*}{ Activity } & \multicolumn{2}{|c|}{2014} & \multicolumn{2}{c}{2015} \\
& $1 s t$ & $2 n d$ & $3 r d$ & $4 t h$ \\
videos & & & & \\
\hline Recording and uploading & & & & \\
Interaction with the & & & & \\
learners \\
Collecting information and & & & & \\
reporting & & & & \\
\hline
\end{tabular}

Fig. 1 Gantt chart of the main activities performed during the experiment.

Each activity was performed at a different period, according to the Fig. 1. The details about the activities involved in the experiment are as follows:

- Recording and uploading videos: All the videos were recorded once per week and uploaded immediately after they were obtained. This activity was carried out during the 1 st period of the project.

- Interaction with the learners: While the videos were uploading, the learners were interested in the information presented, and they were asking different questions related to the topics. The questions were answered once a week to supply new information if needed. This activity was performed during the 1 st 3rd period of the project.
- Collecting information and reporting: With the help of analytic tools supported by YouTube, the information can be collected in order to be presented. This stage corresponds to the last part of the project, where the information obtained is tabulated and presented.

\section{PEDAGOGICAL TOOL DESIGN}

The tool applied in the experiment corresponds to videos with explanations about several topics of Physics. The selected topics form part of the curriculum of Physics courses for engineering programs at HEI in South America.

There have been several studies related to the lack of concentration when the students acquire a passive position mode of learning [11]. The mentioned situation is critical if a long period lecture is considered. Some studies revealed that the concentration decreases after around $15-30 \mathrm{~min}$ of initiation of the lecture [12][13].

Based on the aforementioned context, the length of the videos applied in this experiment is around $10 \mathrm{~min}$. Because the targets of this project are the Hispanic learners, the videos were recorded in Spanish language. There are some videos that, because of the difficulty of the topic, take longer than the mentioned time. The specific length of the videos will be detailed later in this section.

Each video corresponds to the explanation with either one physical law or one example solution in the simplest way without losing the physical meaning or mathematical procedure. The total number of videos is 47 , divided into 3 main groups. Table II shows the group of videos and the number of videos in each group.

The topics of Physics were selected according to the curriculum of the engineering program, and labeled as Group

TABLE II

NUMBER OF VIDEOS GROUPED BY GENERAL TOPICS

\begin{tabular}{|c|c|}
\hline Group & No. of videos \\
\hline Group A & 7 \\
\hline Group B & 24 \\
\hline Group C & 16 \\
\hline & 47 \\
\hline
\end{tabular}

A, Group B and Group C.

Group A corresponds to a basic level of Physics, similar to the college level, i.e., ending the high school. The topics treated are: vectors, kinematics and dynamics. The topics presented in Group B are: linear momentum, angular momentum, work, and energy. Videos related to electrostatics and magnetism were grouped into Group $C$.

The average length of videos belonging to Group $\mathrm{A}$ is 07:40 min; instead, the length for videos of Group B and C are 08:26 and 09:33 min, respectively. The length of the videos corresponding to each group is depicted in detail in Figures 2 4. 


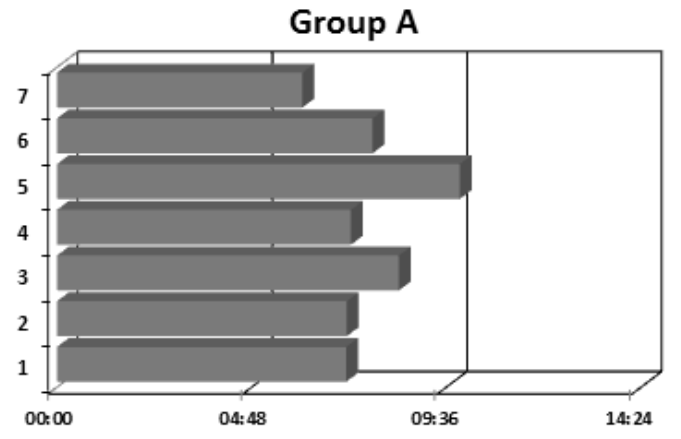

Fig. 2 Length of the videos corresponding to Group A (min)

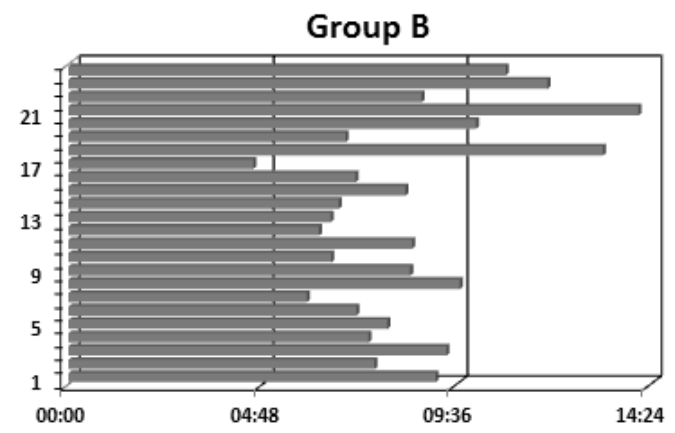

Fig. 3. Length of the videos corresponding to Group B (min)

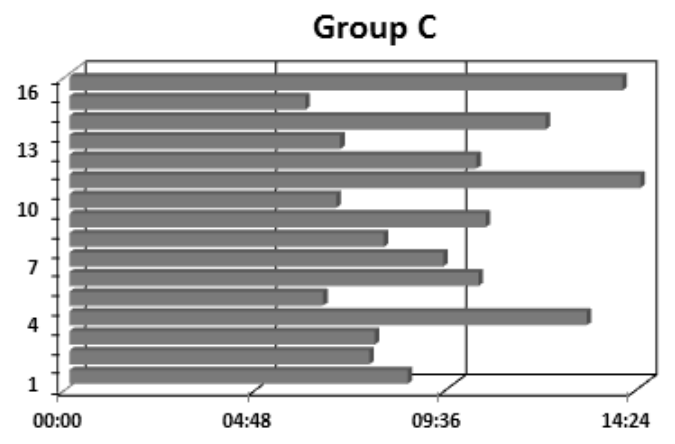

Fig. 4. Length of the videos corresponding to Group C (min)

Considering the time length of all the channel videos, a histogram is presented in Figure 5. The picture shows a very good approximation of a normal distribution. There is only one video in the group of the longest videos (900 - $1000 \mathrm{~s})$, and one video in the group of shortest videos (200 - $300 \mathrm{~s}$ ).

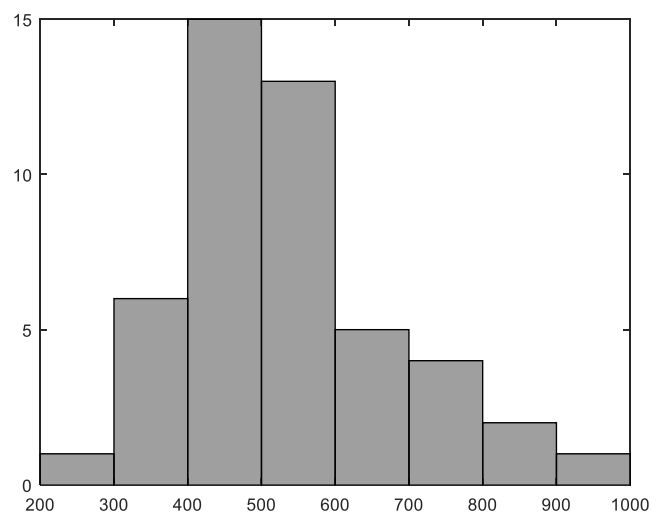

Fig. 5. Histogram distribution of the length of videos for all the channel videos.

On an average, the length of the videos for the channel is around $526.09 \mathrm{~s}$, i.e., $8.77 \mathrm{~min}$. There is no considerable difference between the median value and the average. The median value is equal to $504 \mathrm{~s}$. Based on the histogram, most of the videos have a length between 300 and $900 \mathrm{~s}$ (5 - 15 $\min$ ).

These videos were recorded and uploaded to one personal YouTube channel to analyze the searching and approaching among the learners in different Hispanic countries. The results are given in the next section.

\section{FINDINGS}

As shown in Fig. 1, the data are collected during the 4th period. Different aspects related to the learners are presented in this section. These results are obtained using the analytic tool provided for YouTube.

\section{A. Demographic approaches}

The findings presented in this sub-section correspond to the genre, age, and geographical location of the learners.

Genre approach. Figure 6 depicts the findings related to the genre of learners looking for Physics topics on YouTube based on the videos uploaded.

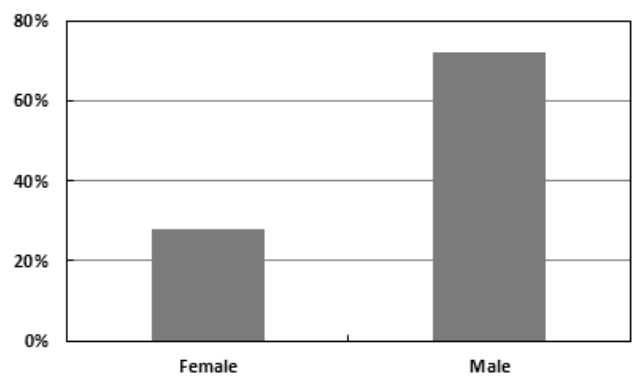

Fig. 6. Graphic representation of the percentage of male and female learners

$14^{\text {th }}$ LACCEI International Multi-Conference for Engineering, Education, and Technology: "Engineering Innovations for 
This result shows that female learners represent somewhat three times lower than the male learners. The male-female ratio is 2.57 , which shows a big gender gap in learners looking for lectures related to Physics at undergraduate level.

Age of the learners. Although there is a considerable difference in the genre of the learners, the age distribution of the genres is similar. The measure found that most of the learners are of age 18 - 24 years, for both males and females.

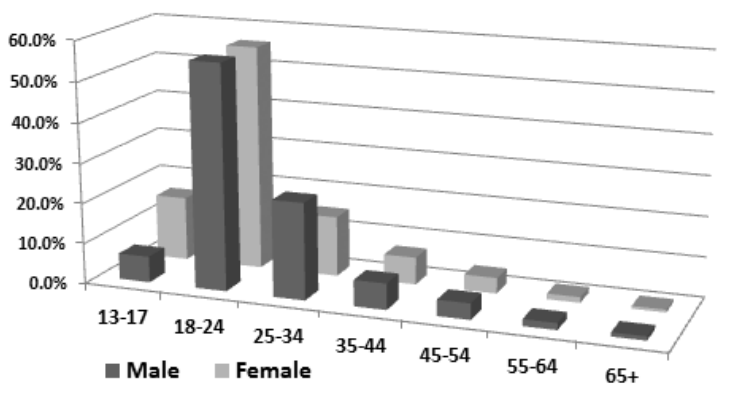

Fig. 7. Age distribution for both male and female learners

In the first and third group, i.e., $13-17$ and 25 - 34 years, there is a difference in behavior. For 13 - 17 years group, female learners are more interested in looking for Physics topics, whereas for 25 - 34 years group, male learners are more interested in the mentioned topics.

Geographical location of the learners. Because the YouTube platform has free access around the world, the videos were watched from 157 countries. In this section, the countries placed in the top 10 position for number of views and watching time are presented.

During the 1st - 3rd period, according to Table 1, the videos obtained 570,561 views. From this, $91.1 \%$ corresponds to the top 10 countries. Figure 8 shows the countries with the most number of views.

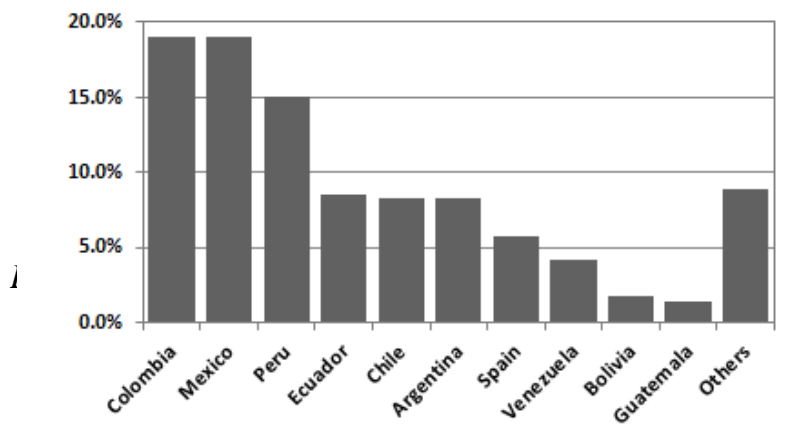

Fig. 8. Countries with the most number of views during the measuring period

The results in Fig. 8 agree with the aim of this study because the countries that participate with most views correspond to countries where the first spoken language is Spanish.

Based on the exposure time of the learners, the picture has slightly changed. This change is presented in Fig. 9.

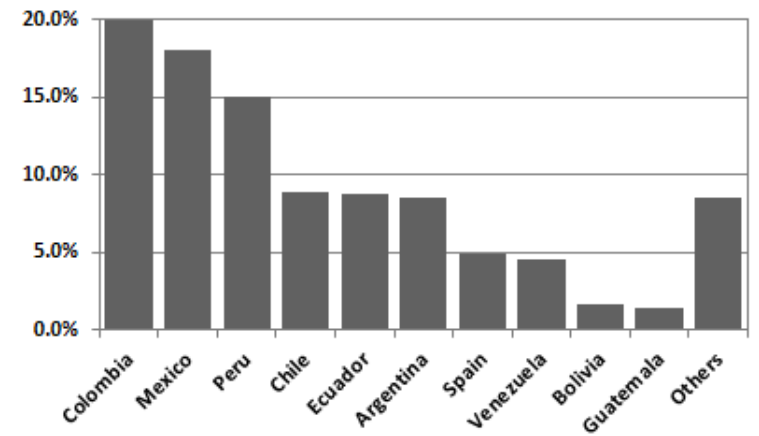

Fig. 9. Countries with the maximum watching time during the measuring period

Comparing Fig. 8 and Fig. 9, there is only one exchange position between the learners from Ecuador and Chile; however, the behavior of the other learners is similar.

\section{B. Quantitative analysis}

The 47 videos were uploaded to the YouTube channel corresponding to a total recorded time of $412 \mathrm{~min}$; it is approximately $6.87 \mathrm{~h}$. However, the time during which the videos were watched is significantly high. Figure 10 shows such a relationship.

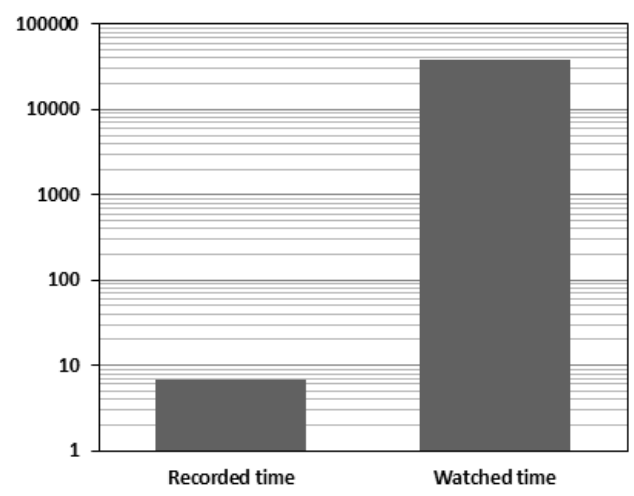

Fig. 10. Comparison between the recorded time and watched time videos

The watched time of the videos is around $37,000 \mathrm{~h}$, i.e., more than 4 years. In that sense, YouTube represents a very good platform to share information during the learning process to reinforce the understanding of different topics of Physics.

The top 10 most watched videos form part of the three groups, but with a slight majority of the videos from Group C 
in comparison with the other groups. The specific topics are given in Table III.

TABLE III

TOPICS OF THE MOST WATCHED VIDEOS IN THE CHANNEL

\begin{tabular}{c|c|c}
\hline Video & Group & $\begin{array}{c}\text { Times } \\
\text { watched }\end{array}$ \\
\hline Torque - explanation & B & 20.7 \\
Parabolic movement & B & 24.7 \\
Acceleration in a sloped plane & A & 18.2 \\
Adding Vectors - 2D & A & 21.4 \\
Biot-Savart Law - part I & C & 10.2 \\
Biot-Savart Law - part II & C & 11.1 \\
Gauss Law - explanation & C & 12.1 \\
Steiner theorem - explanation & B & 15.6 \\
3D vectors - basic explanation & A & 9.8 \\
Lenz Law - explanation & C & 10.4 \\
\hline
\end{tabular}

In Table 3, the first column represents the simplified name of the videos, the second column is the group to which each video belongs, and the last column is equivalent to the number of times that the video was watched. The values of the last column are expressed in thousands, and were calculated as the total time watched over the recorded time for the corresponding video.

\section{Qualitative analysis}

To describe the effect that the group of videos can have on the learners, some comments will be presented in this section. Some of the comments made by the learners compared the traditional lectures with the video that they have watched. The following are some selected comments:

"It was much clearer than the book that I am reading." (Video: Applications of integrals in kinematics)

"What my teacher told a class of two hours you explained in 5 minutes and more clearly." (Video: Ampere Law Explanation)

"I have to lecture on Faraday's law and Lenz and now I understand much better." (Video: Lenz Law - explanation)

"I finally understood how to organize the reference axes... and it took only 8 minutes." (Video: Acceleration in a sloped plane)

"It helped to me for my electromagnetism exam." (Video: Biot-Savart Law - Part II)

"It was understood at the first, in class I was completely lost." (Video: Adding vectors - 2D)

"I understood him better in 13:12 minutes watching the video than in 3 hours per week with my Physics teacher." (Video: Torque - explanation)
"I had long without understanding the Biot-Savart much as looked at my notes. But with this video, explained step by step I managed to understand." (Video: Biot Savart-Part I)

These comments agree with a study that measured the student and teacher perceptions [14] which mentioned that not all of what educators believe to be important or effective coincide with what the learners expect.

Although almost all the comments for the videos are positive, there are some comments where the learners expressed negatively. For instance: "Please, do not use so technical terms," this can occur because when the learner is looking for information, there is no specification of the level of the minimum required knowledge prior to watching the video.

Most of the comments address to conclude that the videos were watched after the learner was trying to understand the topic using their own notes or textbook. Therefore, if these videos are expected to be used in a flipped classroom process [15-17], they can save a lot of time in the learning process.

There is no relationship between the number of comments posted in the videos with the number of views for each video. The latter can occur due to either the difficulty of the topic or the possibility to clarify some aspects beyond the information presented.

\section{CONCLUSIONS}

The present project allows one to know the topics that the learners from Hispanic countries are looking for. Based on the videos of selected topics of Physics uploaded, several conclusions can be presented.

For Hispanic learners, it is most helpful to watch a short video with concise information than a longer video; this can be concluded based on the comments and the retention measurement. The Hispanic male-female ratio of learners looking for Physics videos is around 2.57, which show a huge genre gap. The topics shown in the videos correspond to undergraduate studies in engineering; therefore, most of the learners fall in the age of $18-27$ years. The target learners are mainly, i.e., more than $90 \%$, from countries where Spanish is the mother tongue.

Taking into account the "recorded time" and "watched time", YouTube appears to be a powerful tool for sharing knowledge, explanation, and interaction with learners. Similar tool to the proposed has been applied along with the teachinglearning process in MOOCs, and it can be implemented in flipped classrooms. However, the length of the videos plays an important role in the success of the methodology applied.

According to this experiment, the students like to clarify or reinforce more information related to two- and threedimensional physical situations. Additionally, they had several questions related to the applications of arithmetic tool in Physics, i.e., differential and integral calculus. 


\section{ACKNOWLEDGMENT}

M.E.A. thanks ESPOL and SENESCYT for the support received during his doctoral studies in Sweden.

J.B.M. thanks SENESCYT's scholarship for the financial support received during his master studies in Italy.

\section{REFERENCES}

[1] P. Umarani and D. A. Kumar, "Social media and mobile internet usage among teenagers and young adults: an exploratory study." International Journal of Logistics \& Supply Chain Management Perspectives, vol. 2, no 4, pp. 547, 2013.

[2] D. French, Internet based learning: An introduction and framework for higher education and business. Stylus Publishing, LLC., 1999.

[3] N. S. Chen and L. KO, "An Online Synchronous Test for Professional Interpreters." Educational Technology \& Society, vol. 13, no 2, pp. 153$165,2010$.

[4] M. Zhang, "Prompts-based Scaffolding for Online Inquiry: Design Intentions and Classroom Realities." Educational Technology \& Society, vol. 16, no 3, pp. 140-151, 2013.

[5] N. Selwyn and S. Gorard, "Students' use of Wikipedia as an academic resource-Patterns of use and perceptions of usefulness." The Internet and Higher Education, vol. 28, pp. 28-34, 2016.

[6] R. Mason and F. Rennie. "Using Web 2.0 for learning in the community." The Internet and higher education, vol. 10, no 3, pp. 196203, 2007.
[7] C. O. Rodriguez, "MOOCs and the AI-Stanford like courses: Two successful and distinct course formats for massive open online courses." European Journal of Open, Distance and E-Learning, vol. 15, no 2, 2012.

[8] W. D. Milheim, "Massive open online courses (MOOCs): Current applications and future potential." Educational Technology, vol. 53, no 3, pp. 38-42, 2013.

[9] B. Toven-Lindsey, R. A. Rhoads and J. B. Lozano, "Virtually unlimited classrooms: Pedagogical practices in massive open online courses." The internet and higher education, vol. 24, pp. 1-12, 2015.

[10] M.T. P. Lu and J. Cavazos Vela, "Online Learning Perceptions and Effectiveness of Research Methods Courses in a Hispanic-Serving Higher Education Institute." Journal of Hispanic Higher Education, $1538192714543561,2014$.

[11] W. L. Heward, "Guided notes: Improving the effectiveness of your lectures." Tomorrow's Professor, vol. 495, 2003.

[12] F. Heather, S. Ketteridge and S. Marshall. A handbook for teaching and learning in higher education: Enhancing academic practice. Routledge, 2008.

[13] P. J. Frederick, The lively lecture -8 variations. College teaching, vol. 34, no 2, pp. 43-50, 1986.

[14] S. M. Beaudrie, "Instructional Effectiveness in the SHL Classroom Comparing Teacher and Student Perceptions." Journal of Hispanic Higher Education, 2015.

[15] S. Flumerfelt and G. Green, "Using Lean in the Flipped Classroom for At Risk Students." Educational Technology \& Society, vol. 16, no 1, pp. 356-366, 2013.

[16] M. K. Kim, S. M. Kim, O. Khera, \& J. Getman, "The experience of three flipped classrooms in an urban university: an exploration of design principles." The Internet and Higher Education, vol. 22, pp. 37-50, 2014.

[17] J. O'Flaherty and C. Phillips, "The use of flipped classrooms in higher education: A scoping review." The Internet and Higher Education, vol. 25, pp. 85-95, 2015.

14 ${ }^{\text {th }}$ LACCEI International Multi-Conference for Engineering, Education, and Technology: "Engineering Innovations for 